With the Compliments of Springer Publishing Company, LLC

Research and Theory for
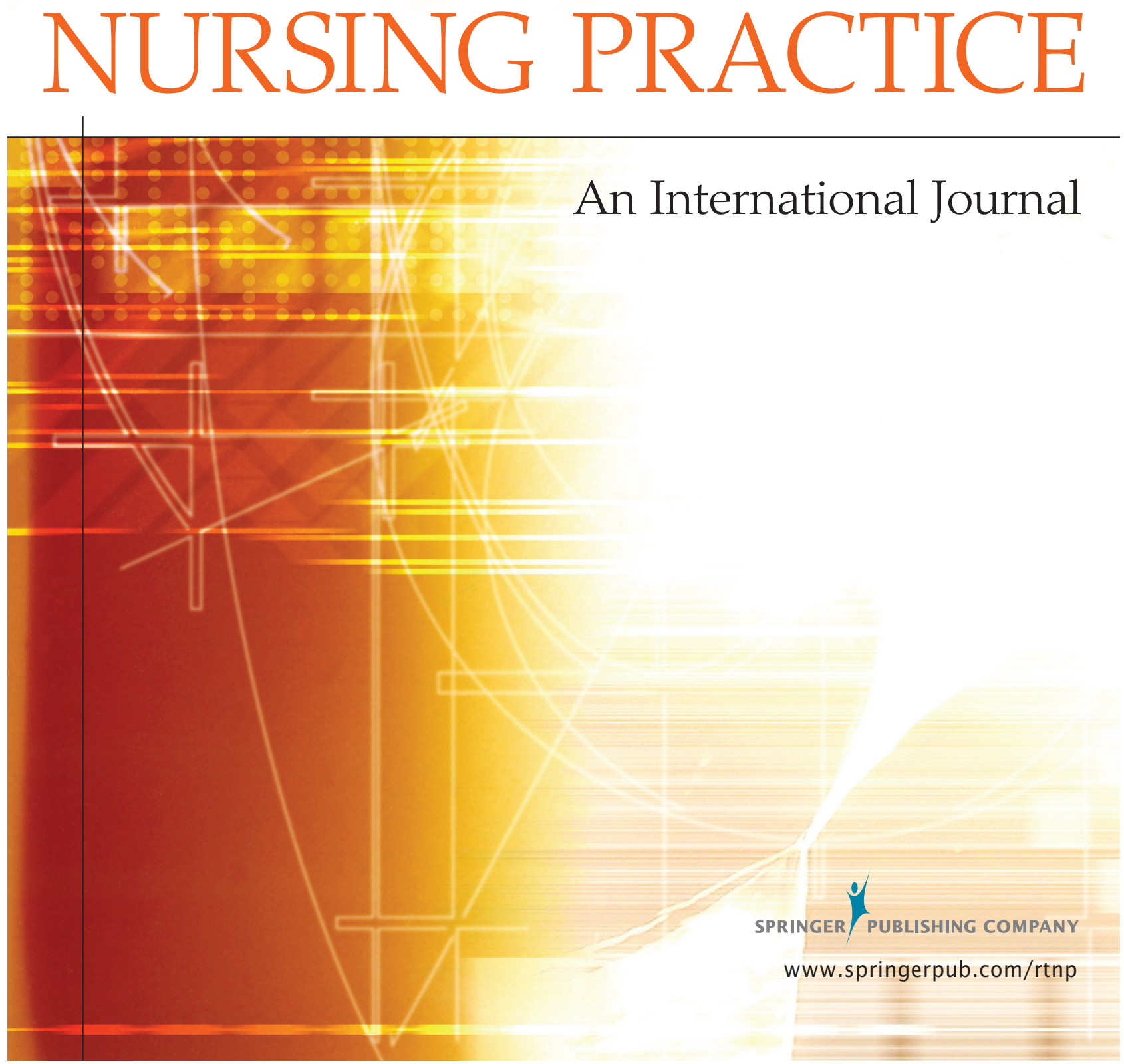


\title{
Relationships Among Self-Efficacy, Social Support, Social Problem Solving, and Self-Management in a Rural Sample Living With Type 2 Diabetes Mellitus
}

\author{
Caralise W. Hunt, PhD, RN \\ Barbara Wilder, DSN, CRNP \\ Michael M. Steele, $\mathrm{PhD}$ \\ Auburn University \\ Joan S. Grant, DSN, RN \\ Erica R. Pryor, PhD, RN \\ Linda Moneyham, DNS, RN \\ University of Alabama at Birmingham
}

Self-management behaviors are important for control of type 2 diabetes mellitus. Therefore, determining factors that promote effective self-management behaviors may be significant for improving the well-being of patients with type 2 diabetes mellitus. This study examined relationships among self-efficacy, social support, social problem solving, and diabetes self-management behaviors. Further, this study evaluated whether social support and social problem solving were mediators of the relationship between self-efficacy and diabetes self-management behaviors in those living with type 2 diabetes mellitus.

Using a cross-sectional, descriptive correlational design, data from a convenience sample of 152 rural people living with type 2 diabetes mellitus were examined. Findings indicated that self-efficacy was a strong predictor of diabetes self-management. The effect of social support on diabetes self-management differed among men and women in the sample. Social support and social problem solving were significantly associated with diabetes self-management in men. Neither social support nor social problem solving were mediators of the relationship between self-efficacy and diabetes 
self-management in this sample. These findings suggest that nurses need to consider implementing interventions to improve patients' self-efficacy and potentially influence diabetes self-management.

Keywords: type 2 diabetes mellitus; self-efficacy; social support; social problem solving; diabetes self-management

$\mathrm{P}$ eople living with diabetes who effectively manage their own care use various self-management behaviors as the cornerstone for control of their type 2 diabetes mellitus (T2DM). These behaviors include physical activity, healthy eating, taking medications as prescribed, self-monitoring of blood glucose, problem solving for blood glucose fluctuations, reducing risk of complications, and psychosocial adaptation (Peeples, Tomky, Mulcahy, Peyrot, \& Siminerio, 2007). Improvements in glycemic control, blood pressure, cholesterol, and quality of life are linked to participation in these self-management activities (Funnell et al., 2007; Jones et al., 2003; Sousa, Zauszniewski, Musil, Price Lea, \& Davis, 2005).

Management of T2DM requires knowledge, skill, and long-term attention to multiple self-care and preventive behaviors. Following a daily self-management plan can be challenging for people living with T2DM. Determining factors that promote effective self-management behaviors is important in improving the physical and psychological well-being of people living with T2DM. Effective self-management contributes to blood glucose control, lowered blood pressure and cholesterol, avoidance of complications, and improved quality of life (Funnell et al., 2007). Selfmanagement behaviors including diet, exercise, blood glucose self-monitoring, and taking medications are related to significant improvements in metabolic control (Jones et al., 2003; Sousa et al., 2005).

Empirical data suggest that individuals with T2DM who have higher self-efficacy, better social support, and more effective problem-solving skills may be better equipped to handle the stresses of living with T2DM and potentially improve their self-management behaviors for this disease (Glasgow, Fisher, Skaff, Mullan, \& Toobert, 2007; King et al., 2010; Nam, Chesla, Stotts, Kroon, \& Janson, 2011; Tang et al. 2005).

Self-efficacy beliefs influence self-management behaviors of people living with T2DM (Wu et al., 2007). Self-efficacy is defined as "people's judgments of their capabilities to organize and execute courses of action required to attain designated types of performances" (Bandura, 1986, p. 391). Individuals with high levels of self-efficacy expect successful goal attainment, whereas those with low levels of self-efficacy doubt their ability to reach goals (Pajares, 2002). Stronger self-efficacy beliefs are positively related to participation in diabetes self-management behaviors (King et al., 2010; Krichbaum, Aarestad, \& Buethe, 2003).

Social support has been linked to self-efficacy and diabetes self-management in previous research. Social support is defined as assistance received from others that has the potential to enhance the recipient's well-being (Schaffer, 2009). 
Social support may be emotional/informational, tangible, and affectionate, as well as positive social interaction provided to individuals (Sherbourne \& Stewart, 1991). People living with T2DM who have adequate support demonstrate higher diabetes self-efficacy than those without adequate support (Coffman, 2008). Low self-efficacy and low levels of social support are viewed as barriers to diabetes self-management (Glasgow, Toobert, \& Gilette, 2001). Participation in selfmanagement behaviors is improved with social support (Nam et al., 2011; Shaw, Gallant, Riley-Jacome, \& Spokane, 2006; Tang, Brown, Funnell, \& Anderson, 2008; Tang, et al. 2005).

Social problem solving refers to "the process of analyzing situations and taking action to correct a problem as it occurs in the natural environment" (D'Zurilla, Nezu, \& Maydeu-Olivares, 2004, p. 11). Previous studies indicate that higher problemsolving ability is related to higher perceived self-efficacy, whereas lower problemsolving ability is related to lower perceived self-efficacy (Jáuregui Lobera, Estébanez, Santiago Fernández, Alvarez Bautista, \& Garrido, 2009; Utz et al., 2008). Social problem solving is an effective approach to improve diabetes self-management behaviors (Glasgow et al., 2007). Problem-solving is necessary to translate knowledge about diabetes into effective self-care management (Bodenheimer, Lorig, Holman, \& Grumbach, 2002).

This study was guided by components of the stress, appraisal, and coping theory of Lazarus and Folkman (1984). According to Lazarus and Folkman, self-efficacy is a method of secondary appraisal that influences coping. Persons with positive self-efficacy beliefs will appraise themselves as able to cope, thereby promoting their coping ability. Persons with negative self-efficacy beliefs will appraise themselves as being unable to cope, thereby inhibiting their coping ability. Social support is a coping resource that if used, will result in positive adaptational outcomes (Lazarus \& Folkman, 1984). Social problem solving supports effective coping and, in turn, can increase a person's long-term self-efficacy (D'Zurilla \& Nezu, 2007). Both situational coping and competence to perform behaviors are enhanced through social problem solving (D'Zurilla \& Nezu, 2007). As coping resources, social support, and social problem solving can be viewed as potential mediators between the cognitive appraisal of stressful situational demands and the response to those demands (D'Zurilla \& Nezu, 2007).

This study examined relationships among self-efficacy, social support, social problem solving, and diabetes self-management behaviors in rural Alabamians living with T2DM. No published studies were found that examined social support and social problem solving as potential mediators of the relationship between self-efficacy and diabetes self-management. Therefore, this study also evaluated whether social support and social problem solving were mediators of the relationship between selfefficacy and diabetes self-management behaviors. This topic is important because if self-efficacy affects diabetes self-management behaviors, and social support and social problem solving are shown to mediate this relationship, then social support and social problem solving skills would be important components of interventions to improve these self-management skills. 
The following research questions were posed for investigation:

a. Does self-efficacy affect diabetes self-management?

b. Does social support mediate the effect of self-efficacy on diabetes selfmanagement?

c. Does social problem solving mediate the effect of self-efficacy on diabetes self-management?

\section{METHODS}

A cross-sectional, descriptive correlational design was used to examine whether social support and social problem solving are mediators of the relationship between self-efficacy and self-management behaviors of people living with T2DM.

\section{PARTICIPANTS}

The sample size for the study was based on pilot study data. A power analysis revealed a sample size of 151 was required for a power of 0.8 and significance level $<0.05$. A convenience sample of 152 adults was included in the study. Participants were selected from three physician offices located in rural counties in Alabama. Inclusion criteria included diagnosis of T2DM, as confirmed by physician or patient chart; residence in a rural county in Alabama; ability to speak English; age 19 and older; and ability to perform their own self-care. Approval for the study was obtained from all three physician offices and a university institutional review board (IRB).

\section{PROCEDURES}

When patients presented for regularly scheduled appointments, designated office personnel assessed their eligibility for study inclusion by comparing the study inclusion criteria with the patient's chart. Participation in the study was voluntary. Office staff and health care providers encouraged patients to participate in the study, but patients were assured that their choice not to participate would not affect their care in any way. Eligible patients were referred to a trained data collector.

Potential participants met with a data collector in a private area of the waiting room or in a private room in the office. The data collector explained the study, verified eligibility, and reviewed the informed consent letter with potential participants. If they agreed to participate, the consent form was signed and a copy was provided to the participant. Following the consent process, the data collector read the survey questions and marked answers provided by the participant. Researcher contact information and a survey number were provided to participants in the informed consent letter so that if participants later decided not to participate in the study, they were able to contact the researcher, give the survey number, and have their survey removed.

Steps were taken to ensure confidentiality including completion of consent forms and surveys in a private room in the office if preferred, exclusion of participant names on surveys, storage of data on an encrypted jump drive, and storage of 
consent forms and surveys in a locked filing cabinet only accessible to the principal investigator.

\section{MEASURES}

Self-report questionnaires were used to collect data. The order of questionnaires was randomized using a random table of numbers.

Sociodemographic Characteristics. The Hollingshead Four Factor Index of Social Status (Hollingshead, 1975) was used to measure sociodemographic characteristics. The Hollingshead Index assesses the four factors of education, occupation, gender, and marital status to estimate social status. The measure accounts for household social status or individual status. Scores range from 8 to 66 , with higher scores indicating higher social status (Nakao \& Treas, 1992). In addition to sociodemographic information assessed with the Hollingshead Index, questions about race, age, and number of years diagnosed with diabetes were included.

Self-Efficacy. Self-efficacy was measured with the diabetes management selfefficacy scale (DMSES). The DMSES is a measure of self-efficacy of people with type 2 diabetes (Van der Bijl, Poelgeest-Eeltnik, \& Shortridge-Baggett, 1999). The 20-item instrument is based on self-care activities people living with type 2 diabetes must perform to manage their diabetes, including eating a hearty healthy diet, participating in physical activity, monitoring blood sugar, taking medications, and monitoring for complications. The 10-point Likert scale assesses patients' confidence in their ability to manage their diabetes, with higher scores indicating higher levels of self-efficacy (Van der Bijl et al., 1999). In this sample, internal consistency assessed using Cronbach's alpha was .90. Previous studies reported internal consistency of the DMSES as .79 and 87 (Coffman, 2008; Van der Bijl et al., 1999).

Social Support. The Medical Outcomes Study (MOS) social support survey (Sherbourne \& Stewart, 1991) was used to measure social support. This 19-item instrument provides an overall functional social support score as well as four social support subscales, including emotional/informational support, tangible support, affectionate support, and positive social interaction. Participants rate the extent to which each type of support is available to them on a 5-point Likert scale. Items are summed for a total score, with higher scores indicating more support (Sherbourne \& Stewart). Cronbach's alpha for the total scale in this study was .96. Cronbach's alpha for subscale scores ranged from .91 to .97. A previous study using the instrument reported an internal consistency of .97 (Sherbourne \& Stewart).

Social Problem Solving. Social problem solving was assessed using the sixthgrade version of the Social Problem-Solving Inventory-Revised Long (SPSI-R:L; D'Zurilla, Nezu, \& Maydeu-Olivares, 2002). This 52-item instrument provides an overall measure of a person's social problem solving ability. The instrument contains five subscales that measure problem orientation and problem-solving style. Respondents report their typical response to problems using a 5-point Likert scale. Items are summed and raw scores are obtained for each subscale and for a total score. Raw scores are converted to standard scores to enable interpretation of scores for a particular age group or population. Higher scores indicate good problem-solving 
ability, and lower scores indicate poor problem-solving ability. Higher scores on the positive problem orientation and rational problem-solving subscales indicate more effective problem solving, whereas higher scores on the negative problem orientation, impulsivity/carelessness, and avoidance subscales indicate more defective problem solving. Overall reliability of the instrument in this study was .87. Cronbach's alpha values for subscales ranged from .74 to .96. Previous studies reported Cronbach's alpha values ranging from .93 to .96 (D'Zurilla et al., 2002).

Diabetes Self-Management Behaviors. Participation in diabetes self-management behaviors was measured using the Summary of Diabetes Self Care ActivitiesRevised (SDSCA) questionnaire (Toobert, Hampson, \& Glasgow, 2000). This 11-item instrument measures frequency of participation in self-management behaviors that include diet, exercise, medication-taking, blood glucose testing, and foot care. Respondents are asked to rate how many of the last 7 days they participated in each self-management behavior. Mean number of days is calculated for each category of self-management behaviors, with higher scores indicating more frequent participation in self-management behaviors. Cronbach's alpha for the total instrument was .72 with individual subscales ranging from .53 to .95 . A previous study that used the SDSCA reported overall internal consistency as .75 with Cronbach's alpha values for individual subscales ranging from .65 to .84 (Johnston-Brooks, Lewis, \& Garg, 2002).

\section{DATA ANALYSIS}

Data were analyzed using Statistical Analysis Software (SAS) version 9.2 with all tests for statistical significance set at an alpha level of .05. Prior to testing research questions, statistical tests for conformance with assumptions and for evaluation of multicollinearity among independent variables were performed. No problems requiring remediation were identified with the data set. Descriptive statistics were performed to characterize sample characteristics and study variables. Correlations among study variables were analyzed using Pearson product moment correlation coefficients.

Mediator and moderator variables increase an understanding of the relationship between independent and dependent variables (Burns \& Grove, 2009). A mediator variable intervenes between independent and dependent variables and explains why a relationship exists between these variables (Polit \& Beck, 2008). Mediator variables do not occur simultaneously with the independent variable but rather they lead to the effect of the independent variable after it has occurred (Baron \& Kenny, 1986). A moderator is a qualitative or quantitative variable that affects the strength or direction of a relationship between independent and dependent variables (Polit \& Beck, 2008).

Mediational analysis was conducted using Baron and Kenny's (1986) method. Baron and Kenny's method uses a series of multiple regression analyses to examine relationships among variables. The steps of mediational analysis are as follows:

Step 1: Examine the relationship between the independent variable and the outcome variable.

Step 2: Examine the relationship between the independent variable and each potential mediator. 
Step 3: Examine the relationship between each potential mediator and the outcome variable, controlling for the independent variable.

Step 4: Examine the relationship between the independent variable and the outcome variable, controlling for each potential mediator.

To evaluate potential moderating effects, a multiple regression analysis was done to determine whether the regression of the dependent variable on the independent variable differs across levels of the moderator (Wuensch, 2009). Moderator effects are noted if the interaction term-the product of the moderator variable and the independent variable-is significantly related to the dependent variable with the independent and moderator variables controlled (Baron \& Kenny, 1986).

\section{RESULTS}

Most research participants were female and had been living with diabetes for 10 years or less. Participants ranged in age from 19 years to 81 years or older with the majority (56.6\%) being between ages 51 and 70 years old. Most participants were African American (58.6\%) and had at least a high school education (57.9\%). Concerning marital status, 33.6\% were single and 36.8\% were married. Descriptive statistics regarding research participants are presented in Table 1.

The mean score for self-efficacy of $7.53(S D=1.52)$ fell within the lower range of "certain can do" or being very sure they could perform diabetes-related self-care activities. The mean social support score was high at $4.18(S D=0.83)$. Total scores for social problem solving were above the middle range with a mean of $14.38(S D=3.1)$. Similarly, two social problem solving subscales-positive problem orientation and rational problem solving -were above middle range at 12.22 and 69.95, respectively. The mean score for the measure of diabetes self-management was $4.59(S D=1.26)$. Descriptive statistics for these study variables are presented in Table 2.

Analysis of correlations among study variables revealed several significant relationships, with weak to moderate correlations (Hinkle, Wiersma, \& Jurs, 2003). Self-efficacy was significantly positively correlated with diabetes self-management $[r(150)=.40]$, social support $[r(150)=.28]$, and social problem solving $[r(150)=.36]$ at $p<.01$. Diabetes self-management was not significantly correlated with social support or social problem solving in this sample. The checking for complications subscale of the diabetes self-management scale was significantly correlated with the total social problem solving score $[r(150)=.17 ; p<.05]$ as well as the constructive problem-solving subscale $[r(150)=.28, p<.01]$. Table 3 illustrates correlations among study variables.

\section{MEdiation Testing}

Using Baron and Kenny's (1986) method for testing mediation, multiple regression analyses were performed to determine whether self-efficacy had a significant effect on diabetes self-management through the mediating variables, social support, and social problem solving. During the model-building process, the only sociodemographic variable significantly related to diabetes self-management was gender; therefore, gender was included as a control variable in all of the regression models. 
TABLE 1. Characteristics of Research Participants $(N=152)$

\begin{tabular}{|c|c|c|}
\hline Characteristic & $n$ & $\%$ \\
\hline \multicolumn{3}{|l|}{ Gender } \\
\hline Male & 52 & 34.2 \\
\hline Female & 100 & 65.8 \\
\hline \multicolumn{3}{|l|}{ Age } \\
\hline $19-25$ & 2 & 1.3 \\
\hline $26-30$ & 2 & 1.3 \\
\hline $31-40$ & 12 & 7.9 \\
\hline $41-50$ & 32 & 21.1 \\
\hline $51-60$ & 41 & 27.0 \\
\hline $61-70$ & 45 & 29.6 \\
\hline $71-80$ & 12 & 7.9 \\
\hline 81 and older & 6 & 3.9 \\
\hline \multicolumn{3}{|l|}{ Race } \\
\hline African American & 89 & 58.6 \\
\hline White & 60 & 39.5 \\
\hline Multiracial & 3 & 2 \\
\hline \multicolumn{3}{|l|}{ Highest level of education } \\
\hline 6th grade or lower & 15 & 9.9 \\
\hline 7th-9th grade & 14 & 9.2 \\
\hline 10th-12th grade & 35 & 23 \\
\hline High school graduate & 46 & 30.3 \\
\hline Some college or certification course & 33 & 21.7 \\
\hline College graduate & 7 & 4.6 \\
\hline Graduate or professional degree & 2 & 1.3 \\
\hline \multicolumn{3}{|l|}{ Marital status } \\
\hline Single & 51 & 33.6 \\
\hline Married & 56 & 36.8 \\
\hline Divorced & 14 & 9.2 \\
\hline Separated & 7 & 4.6 \\
\hline Widowed & 24 & 15.8 \\
\hline \multicolumn{3}{|l|}{ Length of time diagnosed with diabetes } \\
\hline Less than 1 year & 10 & 6.6 \\
\hline $1-5$ years & 58 & 38.2 \\
\hline $6-10$ years & 22 & 14.5 \\
\hline $11-15$ years & 28 & 18.4 \\
\hline $16-20$ years & 16 & 10.5 \\
\hline $21-25$ years & 11 & 7.2 \\
\hline More than 25 years & 7 & 4.6 \\
\hline
\end{tabular}

In Step 1, diabetes self-management was regressed on self-efficacy, controlling for gender. Self-efficacy was significantly associated with diabetes selfmanagement when controlling for gender $[\beta=.332, t(149)=5.39, p<.0001]$. The two potential mediators-social support and social problem solving-were evaluated separately in Step 2. Social support was first regressed on self-efficacy 
TABLE 2. Descriptive Statistics for the Study Variables

\begin{tabular}{llrr}
\hline & $\begin{array}{c}\text { Range of } \\
\text { Possible }\end{array}$ & & \\
Study Variable & Scores & Mean & \multicolumn{1}{c}{$S D$} \\
\hline Diabetes Management Self-Efficacy Scale & $0-10$ & 7.53 & 1.52 \\
MOS Social Support Survey & $0-5$ & 4.18 & 0.83 \\
Emotional/informational & $0-5$ & 4.10 & 0.99 \\
Tangible & $0-5$ & 4.35 & 0.91 \\
Affectionate & $0-5$ & 4.37 & 0.92 \\
Positive social interaction & $0-5$ & 4.05 & 1.10 \\
Social Problem-Solving Inventory-Revised: & $0-20$ & 14.38 & 3.10 \\
$\quad$ Long (Total) & & & \\
Positive problem orientation (PPO) & $0-20$ & 12.22 & 3.79 \\
Negative problem orientation (NPO) & $0-40$ & 13.59 & 10.81 \\
Rational problem solving (RPS) & $0-80$ & 69.95 & 19.06 \\
Impulsivity/carelessness style (ICS) & $0-40$ & 10.57 & 8.34 \\
Avoidance style (AS) & $0-28$ & 8.43 & 6.14 \\
Summary of Diabetes Self-Care Activities-Revised & $0-7$ & 4.59 & 1.26 \\
Diet & $0-7$ & 4.41 & 1.81 \\
Exercise & $0-7$ & 3.27 & 2.38 \\
Self-monitoring of blood glucose & $0-7$ & 4.87 & 2.74 \\
Monitoring for complications & $0-7$ & 4.91 & 2.29 \\
Taking medications & $0-7$ & 6.81 & 0.74 \\
\hline
\end{tabular}

TABLE 3. Correlations Among Study Variables $(N=152)$

\begin{tabular}{|c|c|c|c|c|c|c|c|c|c|}
\hline Study Variable & SE & SS & SPS & $\mathrm{CON}$ & DYS & DSM & EX & $\mathrm{BG}$ & MED \\
\hline Self-efficacy (SE) & - & $.28^{* *}$ & $.36^{* *}$ & $.24^{* *}$ & $.32 * *$ & ${ }^{*} .4^{* *}$ & $.2^{*}$ & .12 & .08 \\
\hline Social support (SS) & & & $.18^{*}$ & $.17^{*}$ & -.13 & .11 & -.02 & .11 & .07 \\
\hline $\begin{array}{l}\text { Social problem- } \\
\text { solving (SPS) }\end{array}$ & & & & - & - & .13 & -.04 & .09 & -.08 \\
\hline Constructive (CON) & & & & & $.27 * *$ & *. .16 & -.01 & .08 & -.12 \\
\hline Dysfunctional (DYS) & & & & & & .08 & .04 & -.07 & -.01 \\
\hline $\begin{array}{l}\text { Diabetes self- } \\
\text { management (DSM) }\end{array}$ & & & & & & & - & - & - \\
\hline Diet subscale (D) & & & & & & & .11 & $.28^{* *}$ & .17 \\
\hline Exercise subscale (EX) & & & & & & & & .13 & -.05 \\
\hline $\begin{array}{l}\text { Blood glucose } \\
\text { subscale (BG) }\end{array}$ & & & & & & & & & .09 \\
\hline $\begin{array}{l}\text { Complications } \\
\text { subscale (COM) }\end{array}$ & & & & & & & & & .03 \\
\hline $\begin{array}{l}\text { Medication } \\
\text { subscale (MED) }\end{array}$ & & & & & & & & & \\
\hline
\end{tabular}

*Significant correlation at $p<0.05$. * Significant correlation at $p<0.01$. 
and gender. Self-efficacy had a significant relationship with social support $[\beta=.156, t(149)=3.61, p<.001]$, controlling for gender. Regression of social problem solving on self-efficacy revealed a significant relationship between the two variables $[\beta=3.84, t(149)=4.66, p<.0001]$, controlling for gender. In the third step of Baron and Kenny's (1986) method, the relationship between social support and diabetes self-management behaviors was evaluated while controlling for self-efficacy and gender. This relationship was nonsignificant, indicating that the third step of mediation for social support was not met. Diabetes self-management was also regressed on social problem solving, selfefficacy, and gender simultaneously. The relationship between social problem solving and diabetes self-management was not significant, indicating that the third step of mediation for social problem solving also was not met for this potential mediator.

According to Baron and Kenny's (1986) definition of mediation, Steps 1 and 2 of the analysis were satisfied. However, in Step 3, neither of the two potential mediators showed a significant effect on diabetes self-management; therefore, Step 4 was not carried out. These findings suggest that social support and social problem solving did not mediate the effect of self-efficacy on diabetes self-management for this sample.

\section{Moderation and Mediation Testing by Gender}

Whereas mediator variables explain how and why a relationship between two variables exists, moderator variables influence the strength of a relationship between variables (Burns \& Grove, 2009). Based on literature that supports the existence of gender differences among study variables (Chlebowy \& Garvin 2006; Misra \& Lager, 2009; Tang et al., 2008), gender was evaluated as a moderator of the relationship between social support and diabetes self-management and social problem solving and diabetes self-management. In a multiple regression model, diabetes self-management was regressed on social support, gender, and an interaction term containing social support and gender. Relationships between gender and diabetes self-management as well as the interaction term and diabetes self-management were significant $(\beta=-3.18, t(148)=-2.71, p<$ $.01 ; \beta=.659, t(148)=2.41, p<.05)$ indicating that the effect of social support on diabetes self-management differed by gender. A second moderation analysis done to evaluate potential moderating effects of gender on the relationship between social problem solving and diabetes self-management revealed no significant relationships.

Because the moderation analysis indicated that the effect of social support on diabetes self-management differed by gender, mediation testing was conducted separately for male and female study participants. In women, the relationship between self-efficacy and diabetes self-management was significant $(p<.05)$; however, the relationship between self-efficacy and social support in women was not significant, indicating that Step 2 of Baron and Kenny's (1986) method for mediation was not met. 
In the sample of men, self-efficacy was significantly related to diabetes selfmanagement $(p<.0001)$. Self-efficacy was also significantly related to social support $(p<.0001)$ and social support was significantly related to diabetes self-management. In the last analysis, Step 4 according to Baron and Kenny (1986), diabetes selfmanagement was regressed on self-efficacy, controlling for social support. Social support became nonsignificant $(\beta=.036, t(49)=.12)$, whereas the relationship between self-efficacy and diabetes self-management remained significant $(\beta=.471$, $t(49)=3.42, p<.05)$, indicating that social support was not mediating the relationship between self-efficacy and diabetes self-management in males.

\section{DISCUSSION}

This study examined whether self-efficacy affected self-management behaviors of people living with T2DM and whether social support and social problem solving mediated the relationship between self-efficacy and diabetes self-management. Self-efficacy did affect diabetes self-management in this sample, but neither social support nor social problem solving mediated this relationship. Variability of scores is important when conducting mediation analysis, and scores in this study appeared to have been fairly homogeneous, perhaps affecting these findings. These findings suggest the importance of examining the effect of social support and social problem solving with samples having greater variability of scores. Furthermore, future research should explore other variables that may explain the relationship between self-efficacy and diabetes self-management.

Self-efficacy was significantly correlated with diabetes self-management. This finding is similar to previous studies in which people living with T2DM who reported higher self-efficacy scores were more likely to report optimal diet, exercise, selfmonitoring of blood glucose, and foot care (King et al., 2010; Sarkar, Fisher, \& Schillinger, 2006; Wang \& Tak-Ying Shiu, 2004; Xu, Toobert, Savage, Pan, \& Whitmer, 2008). Current and previous study findings indicate that people living with T2DM who have higher levels of self-efficacy participate in diabetes self-management behaviors more often. Results of this study also provide support for the stress, appraisal, and coping theory of Lazarus and Folkman (1984). Participants who appraise themselves as able to manage diabetes participate in self-management behaviors, thereby promoting their coping ability.

The study finding that self-efficacy was strongly associated with diabetes selfmanagement emphasizes self-efficacy as an important intervention target in people living with T2DM. Assessment of self-efficacy during an initial visit with new patients and periodic ongoing assessments can provide a means for assessing the degree of support each patient may need to start and maintain behavioral change (Mishali, Omer, \& Heymann, 2011). Nurses can assist patients to improve self-efficacy for diabetes self-management by encouraging participation in decisionmaking about their care, educating them about their condition, motivating them to adopt healthy behaviors, and teaching them to know when to seek help from health care providers (Silva, 2011). Facilitating small, achievable goals can increase 
self-efficacy for managing diabetes and build confidence for achievement of larger, more complex goals (O'Hea et al., 2009). Future studies to evaluate other potential mediators of the relationship between self-efficacy and diabetes self-management would be beneficial to inform nurses and other health care providers about areas of intervention for improving self-management.

Moderation analysis revealed that the effect of social support on diabetes selfmanagement differed by gender. Separate regression analysis by gender found that in women, social support was not significantly related to self-efficacy or diabetes self-management. The analysis with men did reveal significant associations. Social support was significantly related to self-efficacy and diabetes self-management. Previous studies have also noted differences in social support among women and men (Göz, Karaoz, Goz, Ekiz, \& Cetin, 2007; Gucciardi, Wang, DeMelo, Amaral, \& Stewart, 2008; Tang et al., 2008; Toljamo \& Hentinen, 2001). These findings must be viewed with caution. As stated, variability of scores is important when conducting mediation analysis; and sample characteristics in this study may have affected these findings.

Assessment of patients living with T2DM should include availability of social support, sources of support, and quality of the support provided. Once effective sources of social support are identified, strategies for receiving positive support should be determined, including interventions such as educational and support group meetings (Göz et al., 2007). Consideration of gender differences in social support should be given when planning interventions.

Although the complication subscale had low internal consistency and its reliability should be examined further, there were several potential implications for practice and research. Other studies have demonstrated the value of teaching problem-solving skills to manage diabetes-related problems (Glasgow et al., 2007; Mulcahy et al., 2003) . Findings from this study suggest that health care providers should assist patients to develop the use of effective problem-solving skills (especially constructive problemsolving skills) in checking for complications, with an emphasis on prevention. This includes identification of common complications and development of materials to assist patients to identify problems, assess, plan, intervene, and evaluate these problems or complications in conjunction with their health care provider. For example, useful materials would include problems encountered with diabetes management (e.g., complications such as hypertension and other heart-related conditions, stroke, neuropathy, renal dysfunction), how to assess or monitor for each of these problems, specific goals regarding these problems, appropriate interventions to implement, and how to evaluate whether these problems are improving, stabilizing, or need further evaluation by health care providers. Other studies have developed the use of effective problem-solving skills by patients through telephone and face-to-face interventions in conjunction with these written materials that are based on this problem-solving approach (Glasgow, Toobert, Barrera \& Strycker, 2004; Rivera, Elliott, Berry \& Grant, 2008).

Also, further research examining the most effective methods for developing problem-solving skills in patients with T2DM is valuable. For example, what types of problem-solving materials are most useful for patients with T2DM? In teaching 
problem-solving skills, are telephone and face-to-face interventions equally effective or is one method more effective? How many skill training sessions are needed to develop effective problem-solving skills and how much follow-up is necessary to maintain these skills? Are there certain complications that are more useful to prevent and address with the use of effective problem-solving skills by patients?

This study has several limitations, which included the use of a convenience sample and cross-sectional, descriptive correlational design. These limit the generalizability of study findings. Participant's awareness of being in a study also may have affected their response to survey questions. The instrument used to measure social support in this study measured only availability of support. Previous studies that did find significant relationships between social support and diabetes selfmanagement measured availability and sources of social support, satisfaction with social support, and positive and negative support behaviors (Shaw et al., 2006; Tang et al., 2008). Therefore, future studies involving social support should examine not only availability of support but sources, types, and quality of social support for people living with diabetes. Finally, the monitoring for complications and exercise subscales on the SDSCA instrument had low internal consistency values (.53 and .66 , respectively). Further work is needed to develop reliable measures of diabetes self-management.

In conclusion, improvements in self-management behaviors lead to better quality of life and improved glycemic control in people living with T2DM (Song, 2010). The goal of nursing in relation to diabetes is to enhance patients' ability to care for themselves. Identifying factors that improve diabetes self-management is important for achievement of that goal. Interventions should focus on improving self-efficacy, thereby potentially affecting diabetes self-management.

\section{REFERENCES}

Bandura, A. (1986). Social foundations of thought and action: A social cognitive theory. Englewood Cliffs, NJ: Prentice Hall.

Baron, R. M., \& Kenny, D. A. (1986). The moderator-mediator variable distinction in social psychological research: Conceptual, strategic, and statistical considerations. Journal of Personality and Social Psychology, 51(6), 1173-1182. http://dx.doi.org/10.1037 //0022-3514.51.6.1173

Bodenheimer, T. S., Lorig, K., Holman, H., \& Grumbach, K. (2002). Patient self-management of chronic disease in primary care. Journal of the American Medical Association, 288(19), 2469-2475. http://dx.doi.org/10.1001/jama.288.19.2469

Burns, N., \& Grove, S. K. (2009). The practice of nursing research: Appraisal, synthesis, and generation of evidence (6th ed.). St. Louis, MO: Saunders/Elsevier.

Chlebowy, D. O., \& Garvin, B. J. (2006). Social support, self-efficacy, and outcome expectations: Impact on self-care behaviors and glycemic control in Caucasian and African American adults with type 2 diabetes. The Diabetes Educator, 32(5), 777-786. http://dx.doi.org/10.1177/0145721706291760

Coffman, M. J. (2008). Effects of tangible social support and depression on diabetes self-efficacy. Journal of Gerontological Nursing, 34(4), 32-39. http://dx.doi.org/10.3928/0098913420080401-02 
D'Zurilla, T. J., \& Nezu, A. M. (2007). Problem-solving therapy: A positive approach to clinical intervention (3rd ed.). New York: Springer Publishing.

D'Zurilla, T. J., Nezu, A. M., \& Maydeu-Olivares, A. (2002). Social problem-solving inventoryrevised (SPSI-R): Technical manual. North Tonawanda, NY: Multi-Health Systems.

D'Zurilla, T. J., Nezu, A. M., \& Maydeu-Olivares, A. (2004). Social problem solving: Theory and assessment. In E. Chang, T. D'Zurilla, \& L. Sanna (Eds.), Social problem solving: Theory, research, and training (pp. 11-27). Washington, DC: American Psychological Association.

Funnell, M. M., Brown, T. L., Childs, B. P., Haas, L. B., Hosey, G. M., Jensen, B., et al. (2007). National standards for diabetes self-management education. The Diabetes Educator, 33, 599-614. http://dx.doi.org/10.2337/dc07-9923

Glasgow, R. E., Fisher, L., Skaff, M., Mullan, J., \& Toobert, D. J. (2007). Problem solving and diabetes self-management: Investigation in a large, multiracial sample. Diabetes Care, 30(1), 33-37. http://dx.doi.org/10.2337/dc06-1390

Glasgow, R. E., Toobert, D. J., Barrera, M. Jr., \& Strycker, L. A. (2004). Assessment of problemsolving: A key to successful diabetes self-management. Journal of Behavioral Medicine, 27(5), 477-490.

Glasgow, R. E., Toobert, D., \& Gilette, C. (2001). Psychosocial barriers to diabetes selfmanagement and quality of life. Diabetes Spectrum, 14, 33-41. http://dx.doi.org/10.2337/ diaspect.14.1.33

Göz, F., Karaoz, S., Goz, M., Ekiz, S., \& Cetin, I. (2007). Effects of the diabetic patients' perceived social support on their quality-of-life. Journal of Clinical Nursing, 16(7), 1353-1360. http://dx.doi.org/10.1111/j.1365-2702.2005.01472.x

Gucciardi, E., Wang, S. C., DeMelo, M., Amaral, L., \& Stewart, D. E. (2008). Characteristics of men and women with diabetes: Observations during patients' initial visit to a diabetes education centre. Canadian Family Physician, 54(2), 219-227.

Hinkle, D., Wiersma, W., \& Jurs, S. (2003). Applied statistics for the behavioral sciences (5th ed.). Boston: Houghton Mifflin.

Hollingshead, A. B. (1975). Four factor index of social status. Unpublished working paper. Retrieved January 13, 2009, from Department of Sociology, Yale University Web site: http://www.yale.edu/sociology/faculty/

Jáuregui Lobera, I., Estébanez, S., Santiago Fernández, M. J., Alvarez Bautista, E., \& Garrido, O. (2009). Coping strategies in eating disorders. European Eating Disorders Review, 17(3), 220-226. http://dx.doi.org/: 10.1002/erv.920

Johnston-Brooks, C. H., Lewis, M. A., \& Garg, S. (2002). Self-efficacy impacts self-care and HbA1c in young adults with Type I diabetes. Psychosomatic Medicine, 64(1), 43-51.

Jones, H., Edwards, L., Vallis, T. M., Ruggiero, L., Rossi, S. R., Rossi, J. S., et al. (2003). Changes in diabetes self-care behaviors make a difference in glycemic control: The Diabetes Stages of Change (DiSC) study. Diabetes Care, 26(3), 732-737. http://dx.doi.org/10.2337/diacare.26.3.732

King, D. K., Glasgow, R. E., Toobert, D. J., Strycker, L. A., Estabrooks, P. A., Osuna, D., et al. (2010). Self-efficacy, problem solving, and social-environmental support are associated with diabetes self-management behaviors. Diabetes Care, 33(4), 751-753. http://dx.doi .org/10.2337/dc09-1746

Krichbaum, K., Aarestad, V., \& Buethe, M. (2003). Exploring the connection between selfefficacy and effective diabetes self-management. The Diabetes Educator, 29(4), 653-662. http://dx.doi.org/10.1177/014572170302900411

Lazarus, R. S., \& Folkman, S. (1984). Stress, appraisal, and coping. New York, NY: Springer Publishing.

Mishali, M., Omer, H., \& Heymann, A. D. (2011). The importance of measuring self-efficacy in patients with diabetes. Family Practice, 28(1), 82-87. http://dx.doi.org/10.1093/fampra/ cmq086 
Misra, R., \& Lager, J. (2009). Ethnic and gender differences in psychosocial factors, glycemic control, and quality of life among adult type 2 diabetic patients. Journal of Diabetes and Its Complications, 23(1), 54-64. http://dx.doi.org/10.1016/j.jdiacomp.2007.11.003

Mulcahy, K., Maryniuk, M., Peeples, M., Peyrot, M., Tomky, D., Weaver, T., et al. (2003). Diabetes self-management education core outcomes measures. The Diabetes Educator, 29(5), 768-803.

Nakao, K., \& Treas, J. (1992). The 1989 socioeconomic index of occupations: Construction from the 1989 occupational prestige scores (General Social Survey Methodological Report No. 74). Chicago, IL: National Opinion Research Center.

Nam, S., Chesla, C., Stotts, N. A., Kroon, L., \& Janson, S. L. (2011). Barriers to diabetes management: Patient and provider factors. Diabetes Research and Clinical Practice, 93(1), 1-9.http://dx.doi.org/10.1016/j.diabres.2011.02.002

O’Hea, E. L., Moon, S., Grothe, K. B., Boudreaux, E., Bodenlos, J. S., Wallston, K., et al. (2009). The interaction of locus of control, self-efficacy, and outcome expectancy in relation to HbA1c in medically underserved individuals with type 2 diabetes. Journal of Behavioral Medicine, 32(1), 106-117. http://dx.doi.org/10.1007/s10865-008-9188-x

Pajares, F. (2002). Overview of social cognitive theory and of self-efficacy. Retrieved March 21, 2008, from http://www.emory.edu/EDUCATION/mfp/eff.html

Peeples, M., Tomky, D., Mulcahy, K., Peyrot, M., \& Siminerio, L. (2007). Evolution of the American Association of Diabetes Educators' diabetes education outcomes project. The Diabetes Educator, 33(5), 794-817. http://dx.doi.org/10.1177/0145721707307615

Polit, D. E., \& Beck, C. T. (2008). Nursing research: Generating and assessing evidence for nursing practice. Philadelphia: Lippincott, Williams \& Wilkins.

Rivera, P. A., Elliott, T. R., Berry, J. W., \& Grant, J. S. (2008). Problem-solving training for family caregivers of persons with traumatic brain injuries: A randomized controlled trial. Archives of Physical Medicine \& Rehabilitation, 89(5), 931-41. http://dx.doi.org/10.1016/j .apmr.2007.12.032

Sarkar, U., Fisher, L., \& Schillinger, D. (2006). Is self-efficacy associated with diabetes selfmanagement across race/ethnicity and health literacy? Diabetes Care, 29, 823-829. http://dx.doi.org/10.2337/diacare.29.04.06.dc05-1615

Schaffer, M. A. (2009). Social support. In S. J. Peterson \& T. S. Bredow (Eds.), Middle range theories: Application to nursing research (pp. 163-188). Philadelphia: Lippincott, Williams \& Wilkins.

Shaw, B. A., Gallant, M. P., Riley-Jacome, M., \& Spokane, L. S. (2006). Assessing sources of support for diabetes self-care in urban and rural underserved communities. Journal of Community Health, 31 (5), 393-412. http://dx.doi.org/10.1007/s10900-006-9018-4

Sherbourne, C. D., \& Stewart, A. L. (1991). The MOS Social Support Survey. Social Science \& Medicine, 32(6), 705-714. http://dx.doi.org/10.1016/0277-9536(91)90150-B

Silva, D. (2011). Evidence: Helping people help themselves. Retrieved May 15, 2011 , from Health Foundation Web site: http://www.health.org.uk/public/cms/75/76/313/2434/Helping\%20 people\%20help\%20themselves\%20publication.pdf?realName=03JXkw.pdf

Song, M. (2010). Diabetes mellitus and the importance of self-care. Journal of Cardiovascular Nursing, 25(2), 93-98. http://dx.doi.org/10.1097/JCN.0b013e3181c5a364

Sousa, V. D., Zauszniewski, J. A., Musil, C. M., Price Lea, P. J., \& Davis, S. A. (2005). Relationships among self-care agency, self-efficacy, self-care, and glycemic control. Research and Theory for Nursing Practice, 19(3), 217-230. http://dx.doi.org/10.1891/rtnp.2005 19.3.217

Tang, T. S., Brown, M. B., Funnell, M. M., \& Anderson, R. M. (2008). Social support, quality of life, and self-care behaviors among African Americans with type 2 diabetes. The Diabetes Educator, 34(2), 266-276. http://dx.doi.org/10.1177/0145721708315680 
Tang, T. S., Gillard, M. L., Funnell, M. M., Nwankwo, R., Parker, E., Spurlock, D., et al. (2005). Developing a new generation of ongoing diabetes self-management support interventions: A preliminary report. The Diabetes Educator, 31(1), 91-97. http://dx.doi.org/10.1177/ 0145721704273231

Toljamo, M., \& Hentinen, M. (2001). Adherence to self-care and social support. Journal of Clinical Nursing, 10(5), 618-627. http://dx.doi.org/10.1046/j.1365-2702.2001.00520.x

Toobert, D. J., Hampson, S. E., \& Glasgow, R. E. (2000). The summary of diabetes self-care activities measure: Results from 7 studies and a revised scale. Diabetes Care, 23(7), 943-950. http://dx.doi.org/10.2337/diacare.23.7.943

Utz, S. W., Williams, I. C., Jones, R., Hinton, I., Alexander, G., Yan, G., et al. (2008). Culturally tailored intervention for rural African Americans with type 2 diabetes. The Diabetes Educator, 34(2), 854-865. http://dx.doi.org/10.1177/0145721708323642

Van der Bijl, J., Poelgeest-Eeltink, A. V., \& Shortridge-Baggett, L. (1999). The psychometric properties of the diabetes management self-efficacy scale for patients with type 2 diabetes mellitus. Journal of Advanced Nursing, 30(2), 352-359.

Wang, J. Q., \& Tak-Ying Shiu, A. (2004). Diabetes self-efficacy and self-care behaviour of Chinese patients living in Shanghai. Journal of Clinical Nursing, 13(6), 771-772. http://dx.doi.org/10.1111/j.1365-2702.2004.00918.x

Wu, S. F., Courtney, M., Edwards, H., McDowell, J., Shortridge-Baggett, L. M., \& Chang, P. J. (2007). Self-efficacy, outcome expectations and self-care behaviour in people with type 2 diabetes in Taiwan. Journal of Clinical Nursing, 16(11C), 250-257. http://dx.doi .org/10.1111/j.1365-2702.2006.01930.x

Wuensch, K. L. (2009). Continuous moderator variables in multiple regression analysis. Retrieved May 13, 2010, from http://core.ecu.edu/psyc/wuenschk/MV/MultReg/Moderator.doc

Xu, Y., Toobert, D., Savage, C., Pan, W., \& Whitmer, K. (2008). Factors influencing diabetes self-management in Chinese people with type 2 diabetes. Research in Nursing \& Health, 31(6), 613-625. http://dx.doi.org/10.1002/nur.20293

Correspondence regarding this article should be directed to Caralise W. Hunt, PhD, RN, Auburn University School of Nursing, 219 Miller Hall, Auburn, AL 36849. E-mail: huntcar@ auburn.edu 